\title{
Stereotactic radiosurgery for jugular foramen schwannomas: an international multicenter study
}

\author{
Hideyuki Kano, MD, PhD, ${ }^{1}$ Antonio Meola, MD, ${ }^{1}$ Huai-che Yang, MD, ${ }^{2}$ Wan-Yuo Guo, MD, PhD, ${ }^{2}$ \\ Roberto Martínez-Alvarez, MD, PhD, ${ }^{3}$ Nuria Martínez-Moreno, MD, PhD, ${ }^{3}$ \\ Dusan Urgosik, MD, PhD, ${ }^{4}$ Roman Liscak, MD, PhD, ${ }^{4}$ Or Cohen-Inbar, MD, PhD, ${ }^{5}$ \\ Jason Sheehan, MD, PhD, ${ }^{5}$ John Y. K. Lee, MD, ${ }^{6}$ Mahmoud Abbassy, MD, ${ }^{7}$ Gene H. Barnett, MD, ${ }^{7}$ \\ David Mathieu, MD, ${ }^{8}$ Douglas Kondziolka, MD, ${ }^{9}$ and L. Dade Lunsford, MD ${ }^{1}$
}

\begin{abstract}
1Department of Neurological Surgery, Center for Image-guided Neurosurgery, University of Pittsburgh, Pennsylvania; ${ }^{2}$ Departments of Radiation Oncology and Neurological Surgery, Taipei Veterans Hospital, Taipei, Taiwan; ${ }^{3}$ Functional and Radiosurgery Unit, Ruber International Hospital, Madrid, Spain; ${ }^{4}$ Department of Stereotactic and Radiation Neurosurgery, $\mathrm{Na}$ Homolce Hospital, Prague, Czech Republic; ${ }^{5}$ Department of Neurological Surgery, University of Virginia, Charlottesville, Virginia; ${ }^{6}$ Department of Neurological Surgery, University of Pennsylvania, Philadelphia, Pennsylvania; ${ }^{7}$ Department of Neurological Surgery, Cleveland Clinic, Cleveland, Ohio; ${ }^{\circledR}$ Université de Sherbrooke, Centre de Recherche Clinique Étienne-LeBel,

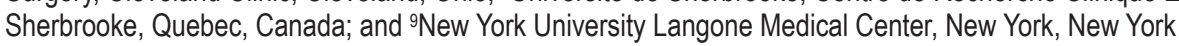

OBJECTIVE For some jugular foramen schwannomas (JFSs), complete resection is possible but may be associated with significant morbidity. Stereotactic radiosurgery (SRS) is a minimally invasive alternative or adjunct to microsurgery for JFSs. The authors reviewed clinical and imaging outcomes of SRS for patients with these tumors.

METHODS Nine participating centers of the International Gamma Knife Research Foundation identified 92 patients who underwent SRS between 1990 and 2013. Forty-one patients had prior subtotal microsurgical resection. The median interval between previous surgery and SRS was 15 months (range 0.5-144 months). Eighty-four patients had preexisting cranial nerve (CN) symptoms and signs. The median tumor volume was $4.1 \mathrm{~cm}^{3}$ (range $0.8-22.6 \mathrm{~cm}^{3}$ ), and the median margin dose was $12.5 \mathrm{~Gy}$ (range 10-18 Gy). Patients with neurofibromatosis were excluded from this study.

RESULTS The median follow-up was 51 months (range 6-266 months). Tumors regressed in 47 patients, remained stable in 33, and progressed in 12. The progression-free survival (PFS) was $93 \%$ at 3 years, $87 \%$ at 5 years, and $82 \%$ at 10 years. In the entire series, only a dumbbell shape (extension extracranially via the jugular foramen) was significantly associated with worse PFS. In the group of patients without prior microsurgery $(n=51)$, factors associated with better PFS included tumor volume $<6 \mathrm{~cm}^{3}(p=0.037)$ and non-dumbbell-shaped tumors $(p=0.015)$. Preexisting cranial neuropathies improved in 27 patients, remained stable in 51 , and worsened in 14 . The CN function improved after SRS in $12 \%$ of patients at 1 year, $24 \%$ at 2 years, $27 \%$ at 3 years, and $32 \%$ at 5 years. Symptomatic adverse radiation effects occurred in 7 patients at a median of 7 months after SRS (range 5-38 months). Six patients underwent repeat SRS at a median of 64 months (range 44-134 months). Four patients underwent resection at a median of 14 months after SRS (range 8-30 months).

CONCLUSIONS Stereotactic radiosurgery proved to be a safe and effective primary or adjuvant management approach for JFSs. Long-term tumor control rates and stability or improvement in $\mathrm{CN}$ function were confirmed.

https://thejns.org/doi/abs/10.3171/2017.5.JNS162894

KEY WORDS jugular foramen schwannoma; stereotactic radiosurgery; Gamma Knife

ABBREVIATIONS CN = cranial nerve; GKS = Gamma Knife surgery; IGKRF = International Gamma Knife Research Foundation; JFS = jugular foramen schwannoma; PFS = progression-free survival; $\mathrm{SRS}=$ stereotactic radiosurgery.

SUBMITTED November 20, 2016. ACCEPTED May 11, 2017.

INCLUDE WHEN CITING Published online November 10, 2017; DOI: 10.3171/2017.5.JNS162894. 
$\mathrm{J}$ UGULAR foramen schwannomas (JFSs) are rare skull base tumors that are most often detected by imaging after patients develop gradually worsening lower cranial nerve $(\mathrm{CN})$ deficits. Additional growth leads to involvement with posterior fossa neurovascular structures and brainstem compression. Microsurgical resection is a common primary approach for JFSs but may be associated with significant postoperative morbidity. ${ }^{1,2,9,12-14,16}$ Stereotactic radiosurgery (SRS) is a minimally invasive alternative or adjunct to microsurgery for JFSs. ${ }^{4,7,10,19}$ The International Gamma Knife Research Foundation (IGKRF) was established to evaluate outcomes of patients with conditions that are relatively rare and to facilitate prospective clinical trials. To better understand both the benefit and risks of SRS, we reviewed the clinical and imaging outcomes of SRS for JFS.

\section{Methods \\ Patient Population}

Nine participating centers in the IGKRF identified 92 patients who underwent a single-stage SRS between 1990 and 2013. All participating centers had individual internal review board approval for participation in this retrospective clinical study: University of Pittsburgh Medical Center $(n=37)$, Taipei Veterans Hospital $(n=16)$, Ruber International Hospital $(\mathrm{n}=10), \mathrm{Na}$ Homolce Hospital $(\mathrm{n}=10)$, University of Virginia $(n=5)$, University of Pennsylvania $(n=6)$, Cleveland Clinic $(n=3)$, Université de Sherbrooke $(n=4)$, and New York University Langone Medical Center $(\mathrm{n}=1)$. A database with selected variables was created and sent to all participating centers. Each site reviewed the medical records of these patients, entered the data in the spreadsheet, and removed all patient identifiers from the data. These de-identified data were sent to the IGKRF data-coordinating center at the University of Pittsburgh Medical Center. Patients with neurofibromatosis Type 2 were excluded from this study. Patients who underwent prior fractionated radiation therapy and staged SRS were also excluded from this study.

\section{Radiosurgery Technique}

After induction of local anesthesia supplemented by intravenous conscious sedation, all patients underwent application of an imaging-compatible stereotactic head frame, and high-resolution MRI was performed. The tumor was assessed using 1- to 2-mm contrast-enhanced volume acquisition images, supplemented by 3-mm T2-weighted scans. The SRS target was defined as the contrast-enhanced tumor volume. Radiosurgery was performed with the Model U, B, C, 4-C, or Perfexion Leksell Gamma Knife (Elekta Inc.). The median tumor volume was $4.1 \mathrm{~cm}^{3}$ (range $0.8-$ $22.6 \mathrm{~cm}^{3}$ ) and the median margin dose was $12.5 \mathrm{~Gy}$ (range 10-18 Gy). All patients were evaluated by MRI at intervals of 3-6 months after radiosurgery. All patients had a minimum of 6 months of follow-up. The follow-up MR images were compared with the intraoperative images, and tumor dimensions were measured in the axial, sagittal, and coronal planes. Progressive disease was defined as a $>25 \%$ increase in the volume of the tumor. Before SRS and at each follow-up interval, $\mathrm{CN}$ and other neurological func- tion was assessed. When clinically indicated, additional studies such as facial electromyography, audiograms, and dynamic swallowing tests were performed. Improvement of $\mathrm{CN}$ deficits was defined as improvement in function of at least 1 preexisting $\mathrm{CN}$ deficit.

For statistical analysis, we constructed Kaplan-Meier plots for progression-free survival (PFS) by using the date of SRS, the date of tumor progression, and the date of last imaging follow-up. We also constructed Kaplan-Meier plots for improvement rates of preexisting $\mathrm{CN}$ deficits and the development of worsening $\mathrm{CN}$ symptoms or signs by using the date of SRS, time to improvement or worsening of $\mathrm{CN}$ deficit, and time of the last clinical follow-up. Univariate analysis was performed on the Kaplan-Meier curves by using the log-rank test (categorical data) and Cox proportional-hazards models (continuous data), with $\mathrm{p}<$ 0.05 set as significant. The Mann-Whitney U-test was used to evaluate the relationship between tumor shape (dumbbell vs others) and continuous variables that included tumor volume and margin dose. Standard statistical processing software (SPSS, version 22.0; IBM Corp.) was used.

\section{Results}

Forty-one patients had undergone prior microsurgical resection (Table 1); 7 patients underwent SRS for tumor progression after microsurgery, and 34 patients underwent SRS for residual tumor after microsurgery. The median interval between previous surgery and SRS was 15 months (range 0.5-144 months). In 51 patients, the JFS was defined by imaging based on location, MRI characteristics, and growth pattern. These patients underwent SRS as the primary surgical procedure. Typically JFS shows a low T1 signal, a high T2 signal, and marked to moderate contrast enhancement on MRI sequences. ${ }^{3,8}$ In comparison, meningiomas have a lower T2 signal and may show calcification and often a sessile appearance because of their dural tail. Glomus jugulare tumors have more intense contrast enhancement and multiple small vascular flow voids. ${ }^{3,15,18}$ At the time of SRS, CN IX and X deficits were seen in 48 patients each (52\%), CN VIII deficits in 42 patients (46\%), CN XI deficits in 29 patients (32\%), CN XII deficits in 25 patients $(27 \%)$, $\mathrm{CN}$ VII deficits in 13 patients (14\%), CN V deficits in 7 patients (8\%), and CN VI deficits in 2 patients (2\%) (Table 2$)$.

\section{Local Tumor Control}

At a median of 51 months (range 6-266 months) after SRS, follow-up imaging showed tumor regression in 47 patients $(51 \%)$, stability in $33(36 \%)$, and progression in 12 (13\%). The PFS was $93 \%$ at 3 years, $87 \%$ at 5 years, and $82 \%$ at 10 years (Fig. 1). In univariate analysis, only a dumbbell shape (extension extracranially via the jugular foramen) was significantly associated with worse PFS ( $p=0.021)$. The 5-year PFS of patients with dumbbell-shaped tumors was $76 \%$, whereas for those with purely intracranial tumors the PFS was $92 \%$. The tumor volume of dumbbell-shaped tumors was significantly larger than that of non-dumbbellshaped tumors $\left(\mathrm{p}<0.001\right.$, median tumor volume $7.7 \mathrm{~cm}^{3}$ vs $3.3 \mathrm{~cm}^{3}$ ). The margin dose for dumbbell-shaped tumors was significantly lower than for smaller, non-dumbbell-shaped tumors ( $\mathrm{p}=0.021$, median margin dose 12.5 Gy vs $13 \mathrm{~Gy})$. 
TABLE 1. Demographics of the patient population

\begin{tabular}{lc}
\hline \multicolumn{1}{c}{ Characteristic } & Value \\
\hline Sex & \\
\hline Male & $44(48 \%)$ \\
\hline Female & $48(52 \%)$ \\
\hline Median age in yrs & $48(14-77)$ \\
\hline Prior microsurgery & $41(45 \%)$ \\
\hline Median interval btwn last microsurgery \& SRS in mos & $15(0.5-144)$ \\
\hline SRS for tumor progression after microsurgery & $7(8 \%)$ \\
\hline SRS for residual tumor after microsurgery & $34(37 \%)$ \\
\hline SRS as initial procedure & $51(55 \%)$ \\
\hline Tumor Type & \\
\hline A-primary intracranial & $43(47 \%)$ \\
\hline B-jugular foramen w/ intracranial extension & $15(16 \%)$ \\
\hline C-primary extracranial w/ foraminal extension & $7(8 \%)$ \\
\hline D-intra- \& extracranial extension: dumbbell shape & $27(29 \%)$ \\
\hline Brainstem compression & $20(22 \%)$ \\
\hline Median tumor vol in cm ${ }^{3}$ & $4.1(0.8-22.6)$ \\
\hline Median margin dose in Gy & $12.5(10-18)$ \\
\hline Median no. of isocenters & $9(1-27)$ \\
\hline Median follow-up after SRS in mos & $51(6-266)$ \\
\hline
\end{tabular}

Values are expressed as the number (\%) or median (range).

The other variables (sex, age, prior resection, recurrent vs residual tumors, interval between prior resection and SRS, brainstem compression, tumor volume, margin dose, and number of isocenters) were not associated with PFS.

In the group of patients without prior microsurgery (n $=51$ ), factors associated with better PFS included tumor volume $<6 \mathrm{~cm}^{3}(\mathrm{p}=0.037)$ and non-dumbbell-shaped tumors $(p=0.015)$. The 5 -year PFS of patients with tumor volume of $\geq 6 \mathrm{~cm}^{3}$ was $77 \%$, but for those with tumor volume of $<6 \mathrm{~cm}^{3}$, it was $93 \%$ (Fig. 2). In the group of patients with prior microsurgery $(n=41)$, there were no significant factors associated with PFS.

\section{Response of Preexisting CN Deficits to SRS}

Eighty-four patients (91\%) had CN disorders at the time of SRS. Eight patients (9\%) had no neurological symptoms or signs before SRS. In these patients, their JFS was found at the time of screening imaging studies performed for unrelated indications. Twenty-seven patients (32\%) with pretreatment neurological deficits had improvement. Symptom improvement occurred between 1.1 and 52.1 months (median 8.8 months) after SRS. The improvement rate of $\mathrm{CN}$ deficits after SRS was $12 \%$ at 1 year, $24 \%$ at 2 years, $27 \%$ at 3 years, and $33 \%$ at 5 years (Fig. 3). None of the following factors (sex, age, prior resection, recurrent vs residual tumors, interval between prior resection and SRS, brainstem compression, tumor volume, margin dose, and number of isocenters) were associated with the improvement rate of $\mathrm{CN}$ deficits.

The most common preexisting $\mathrm{CN}$ disorders were related to CN IX and X dysfunction ( $n=48,52 \%)$. Eighteen of these patients (38\%) improved. The percentage of patients who had improvement in the remaining cases of $\mathrm{CN}$ deficits included the following: $\mathrm{CN} \mathrm{V}$ in $14 \%, \mathrm{CN}$ VI in
TABLE 2. Cranial nerve response after radiosurgery

\begin{tabular}{ccrrrc}
\hline \multirow{2}{*}{$\begin{array}{c}\text { CNs w/ } \\
\text { Deficits }\end{array}$} & No. Before & \multicolumn{4}{c}{ No. (\%) After SRS } \\
\cline { 3 - 6 } & SRS & Improved & No Change & Worse & New Symptom \\
\hline V & 7 & $1(14 \%)$ & $5(71 \%)$ & $1(14 \%)$ & $2(2 \%)$ \\
\hline VI & 2 & $1(50 \%)$ & $1(50 \%)$ & 0 & $1(1 \%)$ \\
\hline VII & 13 & $4(31 \%)$ & $9(69 \%)$ & 0 & 0 \\
\hline VIII & 42 & $8(19 \%)$ & $31(74 \%)$ & $3(7 \%)$ & $1(1 \%)$ \\
\hline IX & 48 & $18(38 \%)$ & $26(54 \%)$ & $4(8 \%)$ & $3(3 \%)$ \\
\hline X & 48 & $18(38 \%)$ & $28(58 \%)$ & $2(4 \%)$ & $4(4 \%)$ \\
\hline XI & 29 & $10(34 \%)$ & $16(55 \%)$ & $3(10 \%)$ & $1(1 \%)$ \\
\hline XII & 25 & $9(36 \%)$ & $15(60 \%)$ & $1(4 \%)$ & $2(2 \%)$ \\
\hline
\end{tabular}

$50 \%$, CN VII in $31 \%$, CN VIII in $19 \%, \mathrm{CN}$ XI in $34 \%$, and CN XII in 36\% (Table 2).

\section{Delayed Progression of CN Symptoms or Signs After SRS}

After SRS, 14 patients (15\%) had delayed onset of additional CN symptoms or signs. In 7 patients this was related to tumor progression (median of 24 months after SRS, range 6-134 months). Seven patients developed new symptoms or signs not associated with definable tumor growth. These 7 patients were found to have adverse radiation effects that developed at a median of 7 months after SRS (range 5-38 months). In all 7 patients with symptomatic adverse radiation effects, these were managed with temporary oral corticosteroids. The rate of development of new $\mathrm{CN}$ disorders was $8 \%$ at 1 year, $11 \%$ at 3 years, $16 \%$ at 5 years, and $16 \%$ at 10 years after SRS (Fig. 4). Factors associated with a higher rate of delayed progression of $\mathrm{CN}$ disorders included dumbbell-shaped tumors $(\mathrm{p}=0.003)$ and measurable tumor progression $(p=0.0001)$. Other factors such as brainstem compression, tumor volume, margin dose, age, prior microsurgery, and preexisting $\mathrm{CN}$ deficits were not associated with a delayed worsening of $\mathrm{CN}$ function.

\section{Additional Management}

Six of 12 patients with tumor progression had repeat SRS at a median of 64 months (range 44-134 months) after their initial SRS. Four patients underwent resection at a median of 14 months after SRS (range 8-30 months). Two patients with tumor progression did not undergo any additional treatment. Because of the development of hydrocephalus in the absence of tumor progression, 1 patient required a ventriculoperitoneal shunt 7 months after SRS. Freedom from the need for additional surgical management was $94 \%$ at 3 years, $87 \%$ at 5 years, and $85 \%$ at 10 years. Characteristics of patients in whom SRS failed are shown in Table 3.

\section{Discussion}

\section{Clinical Presentation}

Jugular foramen schwannomas account for $2.9 \%-4 \%$ of intracranial schwannomas. ${ }^{12,17}$ These tumors may arise from the glossopharyngeal, vagus, or spinal accessory nerves, although it is often impossible to identify the absolute origin of the nerves. ${ }^{12}$ The most common clinical symptoms of JFSs include lower $\mathrm{CN}$ dysfunction such as hoarseness and 

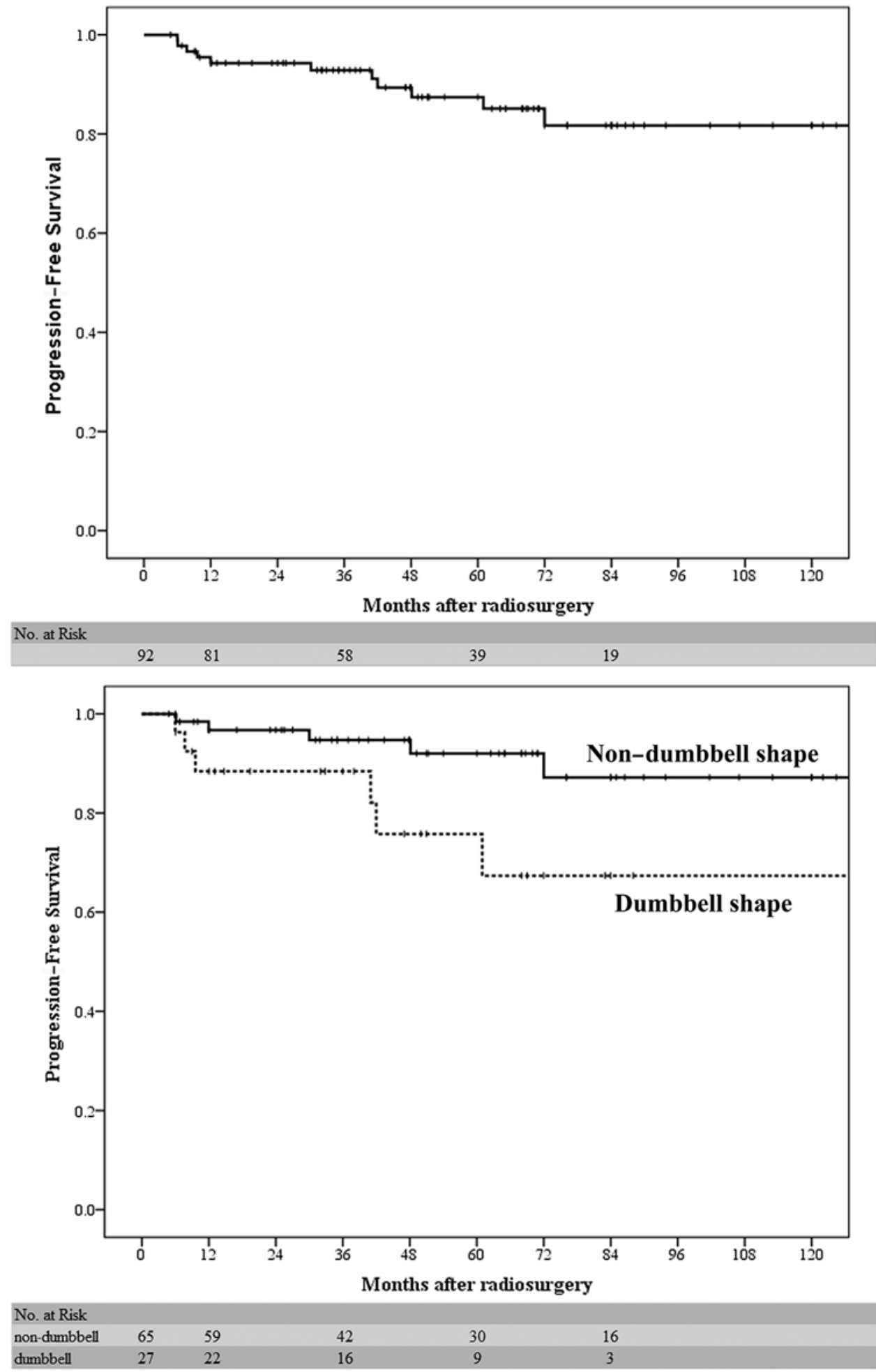

FIG. 1. Upper: Kaplan-Meier estimate of PFS curve after SRS in patients with JFSs. Lower: Kaplan-Meier curves comparing PFS after SRS for dumbbell-shaped tumor versus non-dumbbell-shaped tumors.

swallowing disturbance or hearing loss developing after additional tumor growth. ${ }^{4,12,14}$ In the present study, the most common preexisting clinical symptom included dysfunction of CN IX and X (52\%), followed by CN VIII (46\%).

\section{Microsurgical Resection}

Resection has been considered the primary treatment option for JFSs. Complete resection is often difficult because of the tumor's anatomical location and its relationship 

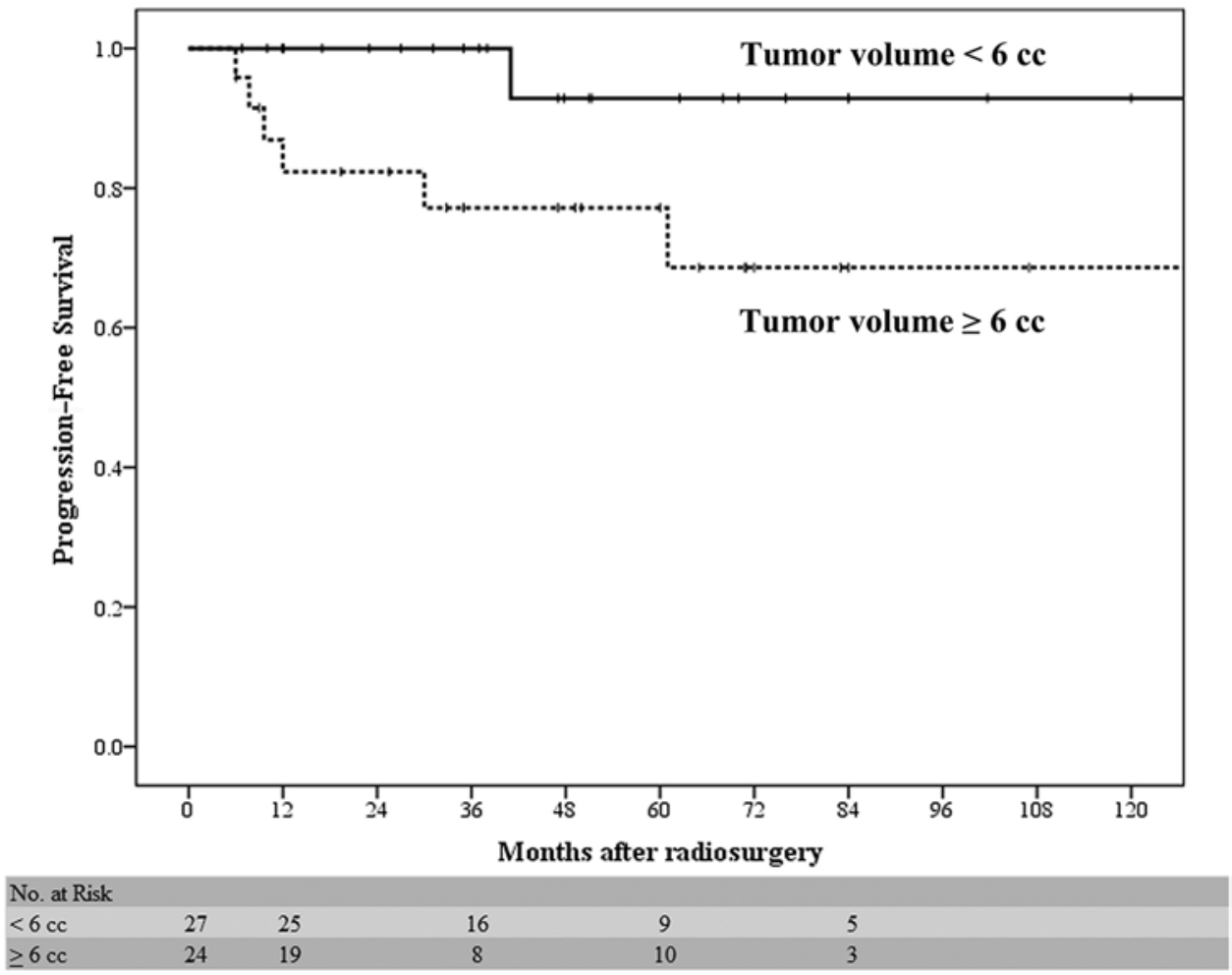

FIG. 2. In the group of patients without prior surgery, Kaplan-Meier curves comparing PFS after SRS for tumor volume of $<6 \mathrm{~cm}^{3}$ versus $\geq 6 \mathrm{~cm}^{3}$.

to adjacent critical $\mathrm{CN}$, brain, and vascular structures. The tumor types have been classified by their growth pattern:5,11 Type A (intracranial type), Type B (intraosseous type),
Type C (extracranial type), and Type D (intra- and extracranial type). A retrosigmoid suboccipital approach ${ }^{12}$ is often performed for Type A JFSs, Type C tumors may require

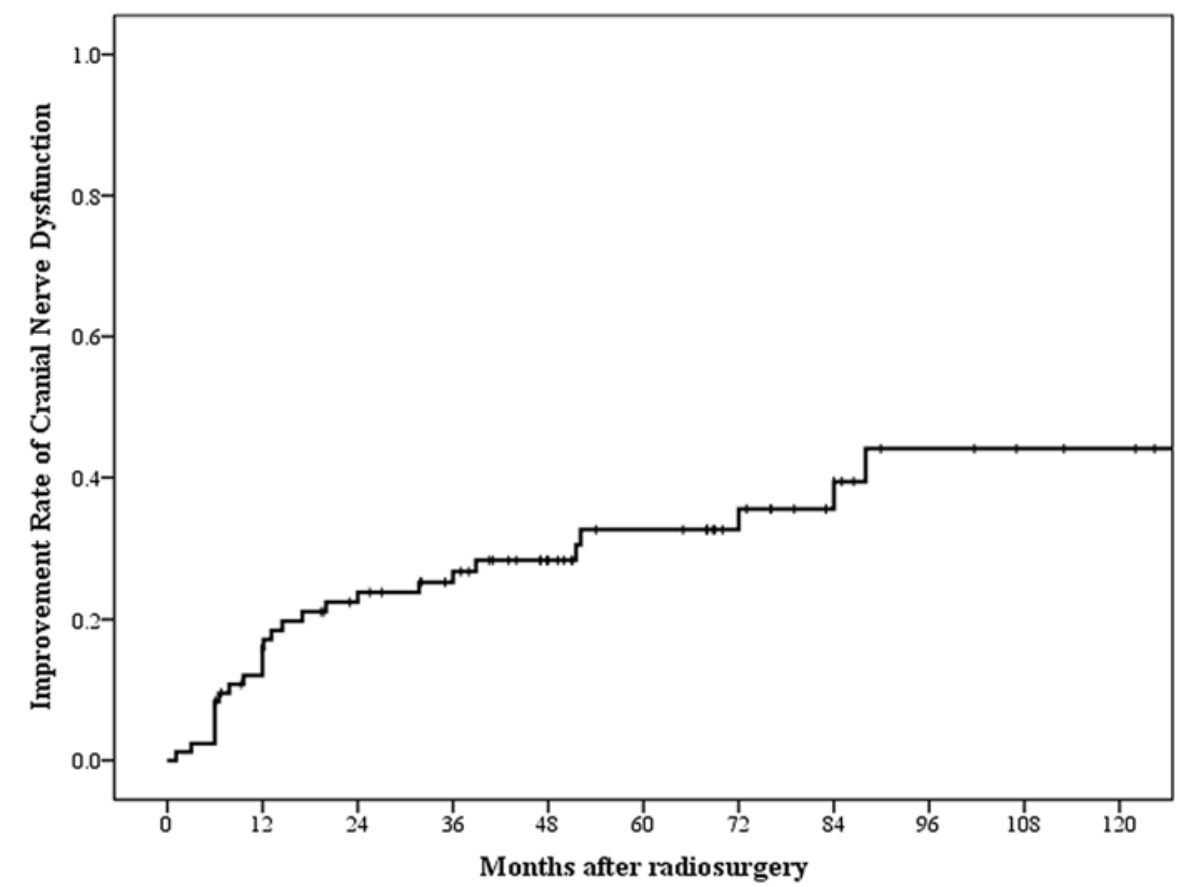

\section{No. at Risk}

$84 \quad 70$

49

30

17

FIG. 3. Kaplan-Meier graph showing improvement rate of $\mathrm{CN}$ dysfunction. 



\begin{tabular}{llllcl} 
No. at Risk & & & & & \\
non-dumbbell & 65 & 57 & 39 & 26 & 17 \\
dumbbell & 27 & 20 & 16 & 9 & 4 \\
\hline
\end{tabular}

FIG. 4. Upper: Kaplan-Meier graph showing deterioration rate of CN symptoms and signs after SRS. Lower: Kaplan-Meier curves comparing the symptomatic deterioration rate after SRS for dumbbell-shaped tumor versus non-dumbbell-shaped tumors.

an infratemporal fossa approach, ${ }^{2}$ whereas a combined retrosigmoid and infratemporal approach may be needed for tumor Types B and D. ${ }^{6}$ Neuromonitoring and image guidance have assisted microsurgical resection of JFSs, with improvement in outcomes. In recent studies, transient $\mathrm{CN}$ VII deficits after microsurgery varied from $11 \%$ to $80 \%$ and permanent CN VII deficits ranged from $4 \%$ to $20 \%$. $1,2,9,13,14,16$ Transient CN VIII deficits after microsurgery varied from 
TABLE 3. Characteristics of patients with failed SRS

\begin{tabular}{|c|c|c|c|c|c|c|c|c|c|c|c|}
\hline $\begin{array}{l}\text { Case } \\
\text { No. }\end{array}$ & $\begin{array}{c}\text { Age/ } \\
\text { Sex }\end{array}$ & $\begin{array}{c}\text { Prior } \\
\text { Surgical } \\
\text { Removal }\end{array}$ & $\begin{array}{l}\text { Preexisting } \\
\text { CN Deficits }\end{array}$ & $\begin{array}{c}\text { Dumbbell } \\
\text { Shape }\end{array}$ & $\begin{array}{l}\text { Tumor } \\
\text { Vol } \\
\left(\mathrm{cm}^{3}\right)\end{array}$ & $\begin{array}{l}\text { Margin } \\
\text { Dose } \\
\text { (Gy) }\end{array}$ & $\begin{array}{l}\text { PD After } \\
\text { SRS } \\
\text { (mos) }\end{array}$ & $\begin{array}{l}\text { CN Deficits } \\
\text { at Last FU }\end{array}$ & $\begin{array}{l}\text { Duration of } \\
\text { Symptom } \\
\text { Deterioration (mos) }\end{array}$ & $\begin{array}{c}\text { Post-GKS } \\
\text { Modality }\end{array}$ & $\begin{array}{c}\text { Time Btwn SRS } \\
\text { \& Post-SRS } \\
\text { Modality (mos) }\end{array}$ \\
\hline 1 & $56 / F$ & No & No & Yes & 13.9 & 12.0 & 6.0 & CN IX, X & 6.0 & Repeat SRS & 12.0 \\
\hline 2 & $48 / \mathrm{M}$ & No & No & Yes & 3.3 & 12.5 & 41.0 & CN IX, X & 41.0 & No & NA \\
\hline 3 & $70 / \mathrm{M}$ & Partial & CN VIII-XII & Yes & 17.0 & 12.5 & 42.0 & CN VIII-XII & 38.0 & Repeat SRS & 44.0 \\
\hline 4 & $62 / F$ & No & CN IX-XI & Yes & 6.1 & 12.5 & 61.0 & CN IX-XI & Stable & No & NA \\
\hline 5 & $47 / F$ & Partial & CN IX-XII & No & 0.93 & 16.0 & 6.1 & CN IX-XII & Stable & Craniotomy & 8.1 \\
\hline 6 & $42 / \mathrm{M}$ & No & CN IX-XII & Yes & 6.3 & 10.0 & 7.7 & CN IX-XII & 7.7 & Craniotomy & 16.3 \\
\hline 7 & $42 / \mathrm{M}$ & Partial & CN IX-CN XI & No & 1.9 & 13.0 & 48.1 & CN IX-XI & Stable & Repeat SRS & 55.1 \\
\hline 8 & $47 / F$ & No & CN VIII & Yes & 2.6 & 13.0 & 134.0 & CN VIII & 134.0 & Repeat SRS & 134.0 \\
\hline 9 & $53 / \mathrm{F}$ & No & CN V, IX-XII & No & 6.1 & 13.0 & 12.0 & CN V, IX-XI & 12.0 & No & NA \\
\hline 10 & $46 / F$ & No & CN XII & Yes & 8.5 & 12.5 & 9.6 & No & Improved & No & NA \\
\hline 11 & $47 / F$ & Partial & No & No & 3.9 & 12.0 & 72.0 & No & NA & Repeat SRS & 72.0 \\
\hline 12 & $42 / F$ & No & CN VIII & No & 6.5 & 12.5 & 30.0 & CN VIII-XI & 30.0 & Craniotomy & 30.0 \\
\hline 13 & $53 / \mathrm{F}$ & Partial & CN IX-XI & No & 1.5 & 13.0 & NA & CN V, IX-XII & 38.1 & No & NA \\
\hline 14 & $72 / \mathrm{M}$ & No & CN VIIII & Yes & 4.0 & 13.5 & NA & CN VIII, X & 8.0 & No & NA \\
\hline 15 & $41 / \mathrm{M}$ & Partial & CN V, VII-XI & Yes & 16.0 & 12.0 & NA & CN V, VII-XI & 6.0 & No & NA \\
\hline 16 & $67 / M$ & No & No & Yes & 9.8 & 12.0 & NA & Unsteady gait & 6.0 & VP shunt & 7.0 \\
\hline 17 & $33 / \mathrm{M}$ & Partial & CN V, VII, IX, X & Yes & 5.1 & 16.0 & NA & CN V-VII, IX, X & 136.2 & No & NA \\
\hline 18 & $19 / \mathrm{F}$ & Total & CN VI-XII & No & 11.1 & 12.0 & NA & CN VI-XII & 24.0 & No & NA \\
\hline 19 & $60 / F$ & No & No & No & 1.4 & 12.5 & NA & CN VIII & 5.0 & No & NA \\
\hline
\end{tabular}

$\mathrm{FU}=$ follow-up; $\mathrm{NA}=$ not applicable; $\mathrm{PD}=$ progressive disease.

$8 \%$ to $45 \%$ and permanent CN VIII deficits after microsurgery varied from $4 \%$ to $20 \%$. Transient lower $\mathrm{CN}$ (CN IX-XI) deficits varied from $25 \%$ to $60 \%$ and permanent $\mathrm{CN}$ IX-XI deficits varied from $10 \%$ to $48 \%$.

Sanna et al. ${ }^{13}$ reported 23 patients with JFS who underwent microsurgical resection. Sixteen patients were found to have at least $1 \mathrm{CN}$ deficit in the preoperative evaluation. A new deficit of the lower CNs developed in 11 patients after microsurgery. Bulsara et al. ${ }^{1}$ reported 53 patients with JFS who underwent microsurgical resection, and 48 of these patients (91\%) achieved gross-total resection. The deterioration of CN IX and X was seen in 16 patients (30\%), with $26 \%$ of the deficits being permanent. Three patients $(6 \%)$ experienced tumor recurrence at a mean follow-up period of 8.4 years. Three patients $(6 \%)$ developed CSF leaks and required reoperation with primary closure of the dural defect. Sedney et al. ${ }^{14}$ reported 81 patients with JFS who underwent microsurgery, and mentioned that a conservative surgical approach resulted in a statistically significant decrease in lower $\mathrm{CN}$ deficits compared with radical gross-total resection. The strategy of radical resection has gradually been replaced by a more conservative surgical approach to preserve $\mathrm{CN}$ function.

\section{Stereotactic Radiosurgery}

Gamma Knife surgery (GKS) has a high tumor control rate, a high rate of $\mathrm{CN}$ preservation, and low morbidity. $4,7,10,19$ Recently, SRS has been used as a primary treatment for medium to small JFSs and as a secondary treatment for residual or recurrent JFSs after microsurgery. Zhang et al. ${ }^{19}$ reported 27 patients with JFS who underwent SRS (2 of whom were not followed), with a mean follow-up of 38.7 months. Tumors regressed in 11 patients, remained stable in 13, and enlarged in 1 patient, who underwent a second SRS procedure. Sixteen patients improved and 9 remained at their pre-SRS clinical status. No patient developed new CN deficits after SRS. Martin et al. ${ }^{7}$ reported 34 patients with JFS with 35 tumors who underwent GKS. The 10year PFS was $94 \%$, with a mean follow-up of 84 months. There were 6 patients with neurofibromatosis Type 2 in their study. All of the patients without neurofibromatosis were in the present study. Peker et al. ${ }^{10}$ reported 17 patients with JFS who underwent GKS. The tumor growth control rate was $100 \%$, with a mean follow-up of 64 months. Six patients (35\%) had improvement of preexisting neurological deficits. Only 1 patient had transient hoarseness.

Recently, Hasegawa et al. ${ }^{4}$ reported the results of an 18-institution Japanese multicenter JFS study in which 117 patients underwent SRS, with a median follow-up of 52 months. Tumor regression was found in 53\% and tumor progression was detected in $11 \%$. The PFS was $91 \%$ at 3 years and $89 \%$ at 5 years. In our study, tumors regressed in $51 \%$ and progressed in $13 \%$ at a median follow-up of 51 months. The PFS was $93 \%$ at 3 years, $87 \%$ at 5 years, and $82 \%$ at 10 years. Tumor control data in the Japanese study were similar to those in our present study. Hasegawa et al. also reported that 20 patients (17\%) developed some degree of symptomatic deterioration after SRS. In the present study, 14 patients $(15 \%)$ had delayed onset of additional CN symptoms or signs. Additionally, we found that dumbbellshaped tumors had a higher rate of progression (Fig. 1). The median volume of dumbbell-shaped tumors was sig- 
nificantly larger than that of non-dumbbell-shaped tumors $\left(\mathrm{p}<0.001,7.7 \mathrm{~cm}^{3}\right.$ vs $\left.3.3 \mathrm{~cm}^{3}\right)$. The median margin dose for dumbbell-shaped tumors was lower $(\mathrm{p}=0.021$, median margin dose 12.5 Gy vs 13 Gy). This may indicate that perhaps dumbbell-shaped tumors had a worse PFS because their larger volumes were treated with lower margin doses. We also found that dumbbell-shaped tumors were significantly associated with a higher rate of symptomatic deterioration (Fig. 4). We suspect that non-dumbbell-shaped tumors are recognized at an earlier stage, which facilitates earlier and more successful intervention with SRS.

Hasegawa et al. ${ }^{4}$ reported that preexisting hoarseness and swallowing disturbances improved in $66 \%$ and $63 \%$ of the patients, respectively. In the present study, 18 of 48 patients (38\%) who had preexisting CN IX and X deficits improved. The rates of improvement in lower $\mathrm{CN}$ function in the report by Hasegawa et al. were significantly higher than those in the present study. This might have been caused by the fact that there are no well-established grading scales for lower $\mathrm{CN}$ dysfunction. Therefore, especially in a multiinstitutional study, the subjective evaluation for lower $\mathrm{CN}$ dysfunction might vary by institution. We believe that the Kaplan-Meier method is a superior way to demonstrate the time course of potential CN symptom improvement after SRS. We found that the improvement rate of $\mathrm{CN}$ deficits after SRS was $12 \%$ at 1 year, $24 \%$ at 2 years, $27 \%$ at 3 years, and $33 \%$ at 5 years.

\section{Study Limitations}

The limitations of this study include the inherent differences in patient selection and treatment afforded by a retrospective multicenter study. In addition, the length of follow-up for some of the patients was $<12$ months, thereby making it difficult to determine the effect of treatment versus the natural history of a skull base tumor such as a JFS. Some tumors were diagnosed by imaging and clinical history, posing the possibility that they in fact were not JFSs. Radiographic and clinical reviews of each case were performed by each participating center. Finally, neuroimaging and radiosurgical techniques have changed over the years. These changes have probably led to earlier detection of JFSs and facilitated improvements in radiosurgical technique.

\section{Conclusions}

Stereotactic radiosurgery provided a satisfactory benefit to the risk profile for patients with residual or newly diagnosed, small-volume, skull base JFSs in this multicenter experience. After SRS, $32 \%$ of the patients with pretreatment neurological deficits had improvement, but $15 \%$ of the patients had delayed onset of additional CN symptoms or signs. The best results were associated with patients with smaller-volume tumors that were detected earlier and had not extended extracranially.

\section{Acknowledgments}

The work described in this report was funded by a grant to Dr. Kano from the Elekta Research Foundation. We thank Dr. Seyed H. Mousavi for assistance in data collection.

\section{References}

1. Bulsara KR, Sameshima T, Friedman AH, Fukushima T: Microsurgical management of 53 jugular foramen schwannomas: lessons learned incorporated into a modified grading system. J Neurosurg 109:794-803, 2008

2. Cho YS, So YK, Park K, Baek CH, Jeong HS, Hong SH, et al: Surgical outcomes of lateral approach for jugular foramen schwannoma: postoperative facial nerve and lower cranial nerve functions. Neurosurg Rev 32:61-66, 2009

3. Eldevik OP, Gabrielsen TO, Jacobsen EA: Imaging findings in schwannomas of the jugular foramen. AJNR Am J Neuroradiol 21:1139-1144, 2000

4. Hasegawa T, Kato T, Kida Y, Sasaki A, Iwai Y, Kondoh T, et al: Gamma Knife surgery for patients with jugular foramen schwannomas: a multiinstitutional retrospective study in Japan. J Neurosurg 125:822-831, 2016

5. Kaye AH, Hahn JF, Kinney SE, Hardy RW Jr, Bay JW: Jugular foramen schwannomas. J Neurosurg 60:1045-1053, 1984

6. Kim CJ, Yoo SJ, Nam SY, Kim SY: A hearing preservation technique for the resection of extensive jugular foramen tumors. Laryngoscope 111:2071-2076, 2001

7. Martin JJ, Kondziolka D, Flickinger JC, Mathieu D, Niranjan A, Lunsford LD: Cranial nerve preservation and outcomes after stereotactic radiosurgery for jugular foramen schwannomas. Neurosurgery 61:76-81, 2007

8. Matsushima T, Hasuo K, Yasumori K, Yoshida K, Hirakata R, Fukui M, et al: Magnetic resonance imaging of jugular foramen neurinomas. Acta Neurochir (Wien) 96:83-87, 1989

9. Nowak A, Dziedzic T, Czernicki T, Kunert P, Marchel A: Surgical treatment of jugular foramen schwannomas. Neurol Neurochir Pol 48:188-195, 2014

10. Peker S, Sengöz M, Kılıç T, Pamir MN: Gamma Knife radiosurgery for jugular foramen schwannomas. Neurosurg Rev 35:549-553, 2012

11. Pellet W, Cannoni M, Pech A: The widened transcochlear approach to jugular foramen tumors. J Neurosurg 69:887-894, 1988

12. Samii M, Babu RP, Tatagiba M, Sepehrnia A: Surgical treatment of jugular foramen schwannomas. J Neurosurg 82:924-932, 1995

13. Sanna M, Bacciu A, Falcioni M, Taibah A: Surgical management of jugular foramen schwannomas with hearing and facial nerve function preservation: a series of 23 cases and review of the literature. Laryngoscope 116:2191-2204, 2006

14. Sedney CL, Nonaka Y, Bulsara KR, Fukushima T: Microsurgical management of jugular foramen schwannomas. Neurosurgery 72:42-46, 2013

15. Sheehan JP, Tanaka S, Link MJ, Pollock BE, Kondziolka D, Mathieu D, et al: Gamma Knife surgery for the management of glomus tumors: a multicenter study. J Neurosurg 117:246-254, 2012

16. Sutiono AB, Kawase T, Tabuse M, Kitamura Y, Arifin MZ, Horiguchi T, et al: Importance of preserved periosteum around jugular foramen neurinomas for functional outcome of lower cranial nerves: anatomic and clinical studies. Neurosurgery 69 (2 Suppl Operative):ons230-ons240, 2011

17. Tan LC, Bordi L, Symon L, Cheesman AD: Jugular foramen neuromas: a review of 14 cases. Surg Neurol 34:205-211, 1990

18. Vogl TJ, Mack MG, Juergens M, Bergman C, Grevers G, Jacobsen TF, et al: Skull base tumors: gadodiamide injection-enhanced MR imaging-drop-out effect in the early enhancement pattern of paragangliomas versus different tumors. Radiology 188:339-346, 1993

19. Zhang N, Pan L, Dai JZ, Wang BJ, Wang EM, Cai PW: Gamma Knife radiosurgery for jugular foramen schwannomas. J Neurosurg 97 (5 Suppl):456-458, 2002 


\section{Disclosures}

Dr. Lunsford is a stockholder with AB Elekta and a consultant for Insightec, DSMB. Dr. Liscak is a consultant for Elekta AB.

\section{Author Contributions}

Conception and design: Kano. Acquisition of data: Kano, Meola, Yang, Guo, Martínez-Alvarez, Martínez-Moreno, Urgosik, Liscak, Cohen-Inbar, Sheehan, Lee, Abbassy, Barnett, Mathieu, Kondziolka. Analysis and interpretation of data: Kano. Drafting the article: Kano, Lunsford. Critically revising the article: all authors. Reviewed submitted version of manuscript: all authors.

Approved the final version of the manuscript on behalf of all authors: Kano. Statistical analysis: Kano. Study supervision: Kano.

\section{Supplemental Information}

Previous Presentations

This study was presented at the 2016 Annual Meeting of the American Association of Neurological Surgeons (AANS).

\section{Correspondence}

Hideyuki Kano, Department of Neurological Surgery, University of Pittsburgh, Ste. B-400, UPMC Presbyterian, 200 Lothrop St., Pittsburgh,PA 15213.email: kanoh@upmc.edu. 